NBER WORKING PAPER SERIES

\title{
FOREIGN COUNTERFEITING
}

OF STATUS GOODS

Gene M. Grossman

Carl Shapiro

Working Paper No. 1915

NATIONAL BUREAU OF ECONOMIC RESEARCH 1050 Massachusetts Avenue

Cambridge, MA 02138

May 1986

Research support from the Alfred P. Sloan Foundation and the National science Foundation is gratefully acknowledged. The research reported here is part of the NBER's research program in International studies. Any opinions expressed are those of the authors and not those of the National Bureau of Economic Research. 
Working Paper \# 1915

May 1986

Foreign Counterfeiting of Status Goods

\section{ABSTRACT}

We study the positive and normative effects of counterfeiting, i.e., trademark infringement, in markets where consumers are not deceived by forgeries. The fact that consumers are willing to pay more for counterfeits than for generic merchandise of similar quality suggests that they value the prestige, or status, associated with brand-name trademarks. Counterfeiters of status goods impose a negative externality on consumers of genuine items, as fakes degrade the status associated with a given label. But counterfeits allow consumers to unbundle the status and quality attributes of the brand-name products, and alter the competition among oligopolistic trademark owners. We analyze two policies designed to combat counterfeiting: enforcement policy which increases the likelihood of confiscation of illegal items, and the imposition of a tariff on low-quality imports.

Gene M. Grossman

Woodrow Wilson School

Princeton University

Princeton, NJ 08544

(609) 452-4823
Carl Shapiro

Woodrow Wilson School

Princeton University

Princeton, NJ 08544

(609) $452-4847$ 


\section{INTRODUCTION}

Counterfeit products account for a growing fraction of world trade. The U.S. International Trade Commission (1984) and Business Week (1985), among others, have documented the extent of illegal copying of the labels and other distinguishing trademarks of brand-name products. These copies, often produced in semi-industrialized countries where labor costs are low and the enforcement of trademark-protection laws is lax, find an all-too-willing market among some discount retailers in the developed countries. Trade officials and legislators in the United States, Japan, and Western Europe have reacted with growing concern to the expansion of this illegal activity, and are seeking new ways to control the phenomenon. These countries individually have taken measures to increase sanctions against importers of counterfeit goods and are bringing pressures to bear on the governments of the source countries. Collectively, the developed countries have agreed to make the drafting of an anti-counterfeiting code one of the priority agenda items for the proposed upcoming round of GATT negotiations.

Despite the evident concern of the business and policy communities about the increasing incidence of foreign counterfeiting, the practice has attracted little attention from economists. This is somewhat surprising, in view of the interesting and insightful crime-theoretic analyses that have been developed of such related phenomena as smuggling and illegal immigration. ${ }^{1}$ In this paper, which complements earlier work reported in Grossman and Shapiro (1986), we continue our efforts to understand the causes and consequences of counterfeitproduct trade and the efficacy of alternative policies that might be used to control it.

1. See, for example, Bhagwati and Hansen (1973), Pitt (1981), Martin and Panagariya (1984) and Ethier (1986). 
For analytical purposes, we might regard the markets for counterfeit products as being of two types. In one type of market, consumers cannot readily observe the quality of the goods that they purchase, nor can they easily distinguish copies from authentic merchandise. In these markets with imperfectly-informed consumers, trademarks protect firms' investments in their reputations, and counterfeiting represents an infringement on a firm's property rights to its customers' goodwill. This practice, which we term deceptive counterfeiting, was the subject of our earlier paper. In other markets, however, consumers often know (or strongly suspect) when they are purchasing a counterfeit. They distinguish fakes from legitimate, brand-name goods either by close inspection, or because the legitimate producers can effectively signal their authenticity by restricting and monitoring the distribution channels through which their goods are sold. We investigate this type of non-deceptive counterfeiting in the current paper. ${ }^{2}$

Why would a consumer knowingly purchase a counterfeit item? One possibility is that the product offers good value for money in the light of its true quality or usefulness. But this explanation raises the question of why the counterfeiters would incur the risks associated with illegal copying, when in a world of perfect information they could equally well compete for customers lawfully. ${ }^{3}$ If the copies really were on a par with legitimate products but were

2. In practice, of course, it may not be so easy to characterize markets for counterfeit products as being of one sort or the other. Consumers may differ in their ability to distinguish fakes, so that the same counterfeit good may be purchased unwittingly by some but intentionally by others.

3. Notice that we are drawing a distinction here between counterfeiting, defined as the illegal copying of a brand-name label or other distinguishing trademarks, and patent or copyright infringement, where the protected rights to intellectual property are being violated. In instances of the latter practices, the pirating firm would not be able to compete for customers lawfully, even though the copies may be equal in quality to the originals. 
offered at a lower price, then consumers would prefer these to the branded merchandise. In fact, counterfeits generally are of much lower quality than the authentic goods that they imitate (see U.S. House of Representatives Committee on Energy and Commerce, 1983). So the counterfeiters often compete instead in the submarkets for low-quality goods. But there they suffer a cost disadvantage relative to producers of generic products (i.e., those not associated with a well-known manufacturer), who do not face the extra expenses associated with mimicking the design and label of the brand-name goods and with any potential penalties from being caught.

An alternative explanation is that the label and identifying design characteristics (e.g., a logo, or a distinctive fabric pattern) are themselves of value to consumers. Such is the case for status goods, i.e., those goods for which the mere use or display of a particular branded product confers prestige on their owners, apart from any utility deriving from their function. The counterfeiting of status goods, then, deceives not the individual who purchases the product, but rather the observer who sees the good being consumed and is duly (but mistakenly) impressed.

The counterfeiting of status goods has a number of implications for the functioning of these markets. First, counterfeiters unbundle the status and quality aspects of the product, and thereby allow some consumers to purchase the former who would not be willing to pay the high price of purchasing the two together. Counterfeiters also dilute the market power of the producers of what are, by definition, differentiated products. At the same time, the illegitimate producers impose an externality on trademark holders by reducing the snob appeal of their products. Legitimate firms are unable to offer their customers the prestige associated with a small, select network of users, when a fringe of imitators allows consumers with less discerning tastes to enter the club. These 
conflicting welfare effects of counterfeiting are the focus of the analysis that follows .

In Section 2 we develop an equilibrium model of the market for a status good, adopting for the purpose the demand structure first suggested by Leibenstein (1950). We allow for the possibility of counterfeiting, and note the conditions under which it will occur and the effects that it has on the market. Section 3 contains our welfare analysis for the case of a fixed number of domestic trademark owners. We study there the efficacy of two alternative policies: enforcement and confiscation, and tariffs on low-quality goods. In Section 4 we explore the case of free entry, thereby incorporating the effects of counterfeiting on the number of status goods developed. Our findings are summarized in a brief concluding section.

II. THE MODEL

We develop a relatively simple model that captures the main features of the market for a status good such as wristwatches. Watches are available in different qualities. Domestic firms produce high-quality goods and brand these with their trademarks and other identifying, design characteristics. These trademarks confer status on the owners of such items, which they value above and beyond the inherent worth of the watches qua timepieces. For simplicity, we assume that all high-quality watches of a given status level are perfect substitutes.

Foreign-owned firms produce only low-quality watches. Some of these are labeled honestly (including those that are marked, by agreement, with the label of a domestic retailing outlet), and are exported to the domestic market as generic products. Since these products would not be worn by those who value a 
fine watch, and since their manufacturers have not invested in the advertising necessary to develop snob appeal, the generics offer no utility other than as keepers of time. Other, less scrupulous, foreign firms manufacture look-alike products that mimic the external attributes of the prestigious brands. These low-quality imitations do not fool any buyers, who are assumed to be able to judge quality on close inspection or infer it from the place of purchase. However, the fakes do mislead the casual observer, so the owners of such watches enjoy the status associated with the "real thing".

Consumers differ in their taste for quality (and for prestige), perhaps due to differences in their levels of income or wealth. We index domestic consumers by $y \in[0, N]$, where $N$ is their total number. Each consumer has use for at most one watch. Let $\mathrm{L}(\mathrm{y})$ and $\mathrm{H}(\mathrm{y})$ denote the "functional" utility that consumer $\mathrm{y}$ derives from a watch of low and high quality, respectively. We define $V(y) \equiv H(y)-L(y)$, and order consumers so that $V^{\prime}(y)<0$ (i.e., consumers with low indexes value quality most highly).

If consumer y buys a high-quality, brand-name product, he enjoys, in addition to $H(y)$, an additional benefit, $S(x, y)$, owing to the snob appeal of the good. Here $x$ measures the prestige associated with the particular brand. We assume, following Leibenstein (1950), that the prestige of a given brand is negatively related to the total number of consumers who sport its label.

The network of users of a particular branded item includes not only those purchasing the genuine articles, but also those who buy copies of it. It follows that the consumer with index y derives utility (gross of payment) of $L(y)+$ $S(x, y)$ from the purchase of a counterfeit product. By appropriate definition of $S(\cdot, \cdot)$, we can take $x$ simply to be the total number of sales of a given label including the counterfeits. Then we have $S_{x}<0$, which captures the notion that 
imitations degrade the prestige of status goods. ${ }^{4}$ To the extent that status also depends directly on the brand-specific market share of counterfeits, fakes would degrade status even more sharply than in our model.

Our final assumption regarding demand is that $\mathrm{S}_{\mathrm{y}}<0$, i.e., that consumers who value quality relatively little also place a lower value on prestige. This could be because high-income consumers can better afford both quality and status, or because true lovers of the product better appreciate its finer attributes, from whence derives their snobbery. In any event, this assumption is not unlike that commonly made in the literature on price discrimination, that individuals' demand curves do not cross:

Turning to the supply side of the model, we assume that there are $m$ distinguishable trademarks, each owned by a different domestic firm. Until Section 4, where we allow for entry and exit, we take $m$ as fixed. Each domestic firm (e.g., brand i) produces high-quality watches either at home or abroad (whichever is efficient) at constant marginal cost c. It sells these goods at price $p_{i}$, earning profits (gross of any development costs) of $\pi_{i}=\left(p_{i}-c\right) z_{i}$, where $z_{i}$ represents output for the domestic market. 5

Low-quality, generic products are manufactured abroad (for reasons of comparative advantage) at constant marginal cost a. Counterfeits also originate outside the home borders, both for the standard trade-theoretic reasons and due to the fact that enforcement of trademark-protection laws is less stringent there. The unit cost of producing a counterfeit, $b$, is at least as high as that

4. We could permit prestige to increase initially with sales until some threshold is reached. In our model, counterfeiting would always push sales beyond this threshold, however, so there is no loss of generality in assuming that $S$ is monotonic in total sales.

5. Since we are assuming that status networks are location specific and that marginal costs of production are constant, we may ignore any profits that the firm makes on sales abroad. 
of producing a generic good, and may be higher if there are extra expenses involved in making the copy resemble the name-brand good.

Counterfeiters must bear a second, additional expense (relative to their more honest countrymen), which stems from the illegality of their activity. If some of their illicit ware is discovered by their local government, by the legitimate producers, or by the home government, penalties may be imposed.

To date, policing by local authorities in the source countries has been lax, although there is some evidence of a recent shift in policy due to pressures from the United States (see New York Times, March 30, 1986). In any event, we include in $b$ any penalties that might be imposed by the foreign government. Discovery of counterfeits by the target firm sometimes elicits legal retribution. However, affected firms report that this approach to the counterfeit problem generally has not been fruitful, due to the fly-by-night nature of the culpable parties and the fact that they usually lack attachable assets. ${ }^{6}$ For this reason, we assume that the penalties that can be imposed by the trademark holder are negligible. Finally, the home government may uncover some counterfeits via its enforcement policy, either at the border (if the transformation into look-alike products has been completed by then), or once the bogus goods reach the retail outlets. Discovery by the home government often leads to confiscation. We assume that this occurs with probability $\phi$, which we treat as a policy variable reflecting

6. See, for example, the testimonies of Kenneth Umans and Richard A. Wallens before the Subcomittee on Crime, U.S. House of Representatives Committee on the Judiciary (1985). Umans reports from his experience as a litigator on behalf of plaintiffs in counterfeiting actions that "if a corporation is sued, an injunction may stop that particular corporation from repeating its counterfeiting transactions, but it doesn't cause a defendant to suffer financially. Further, many defendants simply form new corporations to escape the strictures of an injunctive order." (p.204) 
the resources that the government devotes to enforcement of its trademark protection laws. 7

We complete our description of the model with assumptions about market structure and conduct. Free entry prevails among the foreign firms. This ensures zero profits for producers of both low-quality watches and counterfeits. Let $q$ be the price of a counterfeit. (Low-quality imports sell for a.) Then we have $q=b /(1-\phi)$, where we recognize that the unit cost of production, $b$, must equal the expected revenue from a copy, $q(1-\phi)$. Home firms choose outputs, $z_{i}$, as in Cournot competition. Thus, our model has the structure of a Cournot oligopoly facing a competitive fringe.

To understand the nature of equilibrium, it is instructive to begin with the case of a single trademark owner $(m=1)$. This monopolist chooses its output to maximize profits, recognizing that counterfeits and generics are available in elastic supply.

Suppose, provisionally, that the monopolist finds it optimal to allow counterfeiters to make positive sales. Then for any output level, $z$, the monopolist will find his market among consumers with low indexes y, while consumers with intermediate indexes will purchase counterfeits and those with high indexes will opt for generics. Consumer $z$ (the marginal sale for the monopolist) must be indifferent between a genuine, high-quality watch and a counterfeit. This indifference requires that the premium for high-quality products over copies, $p-q$, be equal to the consumer's valuation of quality, $V(z)$, or

7. The exact form of the supply curve for counterfeits in our model depends on whether the extra costs associated with mimicking the design and label of a name-brand good (b-a) are borne before or after the risk of confiscation is met. In the event of the latter, these costs are not incurred on confiscated merchandise. To avoid becoming taxonomic in our analysis, we simply assume here that the extra costs occur beforehand. 


$$
p=V(z)+q
$$

Recall that $x$ is the total sales of genuine and counterfeit branded items. The consumer with index $x$ therefore is the one who is indifferent between a counterfeit watch and a generic one. The status appeal of the copy must just compensate for its higher price, i.e.,

$$
S(x, x)=q-a
$$

This equation alone gives the equilibrium network size, $x^{*}$, assuming that some counterfeiting occurs.

Equation (1) gives the inverse demand curve facing the trademark owner, provided that he chooses $z<x^{\star}$. Greater levels of output deter entry by counterfeiters, so that the marginal consumer for the monopolist then is the one who is indifferent between his product and a generic. This gives $H(z)+S(z, z)-$ $p=L(z)-a$, or

$$
p=V(z)+S(z, z)+a, \quad \text { for } z>x^{*}
$$

We show these two sections of the inverse demand curve, and the corresponding marginal revenue curve, in Figure 1.

The monopolist maximizes profit by setting marginal revenue equal to marginal cost, as usual. This can occur on either segment of the demand curve, 
but for now we will stress the equilibria that result when counterfeiters are not deterred. ${ }^{8}$ Then the firm's first order condition implies

$$
V(z)+z V^{\prime}(z)+q=c
$$

In such a counterfeiting equilibrium the prestige offered by the monopolist, $x^{*}$, is beyond its control. The firm competes for customers with the counterfeiters, who offer a similar level of status but lower quality products.

Finally, there might be a consumer (or perhaps several) who is indifferent between purchasing a generic product and buying no watch at all. This consumer has $L(y)=a$. We denote the total number who purchase a watch by $w$, with $w \leq N$. We now are prepared to extend the analysis to oligopoly, with $m>1$. We restrict our attention to symmetric equilibria among the m domestic firms. ${ }^{9}$ In symmetric counterfeiting equilibria, all brands offer the same snob appeal, and, as above, each firm recognizes that it cannot control the status of its own product. Any effort by firm $i$ to increase the snob appeal of its products will simply call forth additional counterfeits of its label until the status of brand $i$ is equal to that of the others.

8. The necessary and sufficient condition for counterfeiting to occur is $c-q^{>} V\left(x^{*}\right)+x^{*} V^{\prime}\left(x^{*}\right)$. We will return to consider limit-pricing equilibria, in which entry by counterfeiters is deterred, when we discuss the welfare implications of counterfeiting in Section 3B below.

9. As we shall see, a symmetric equilibrium always exists under the usual convexity assumptions. We believe that asymmetric equilibria also exist for some parameter values. In these asymmetric equilibria, highly prestigious products are counterfeited, while less prestigious goods are not. We do know, however, that asymmetric equilibria cannot exist when $S(x, y)$ is independent of $y$, i.e., when all consumers value status equally. 
Some additional notation is helpful. Let $x_{i}$ be the total sales, including copies, of watches bearing firm $i$ 's label. Define $Z \equiv \Sigma z_{i}$ and $X \equiv \Sigma x_{i}$. Finally, let $z$ and $x$ denote per-firm variables in a symmetric equilibrium.

If $Z$ consumers in total are to buy high-quality watches, then the premium for quality must adjust so that

$$
\mathrm{p}=\mathrm{V}(Z)+\mathrm{q}
$$

The consumer $X(=m x)$ is indifferent between purchasing one of the counterfeits, each offering prestige $x$, and the generic product. Since each of these alternatives provides the same low level of quality, the indifference condition requires

$$
\mathrm{S}(\mathrm{x}, \mathrm{mx})=\mathrm{q}-\mathrm{a} .
$$

The outcome of the Cournot competition among trademark owners is found as usual. Each firm takes its rivals' outputs as given, and chooses $z_{i}$ to maximize $\pi_{i}$. Noting $\left(1^{\prime}\right)$, each faces a marginal revenue curve (in the range of positive sales of counterfeits) given by $M R_{i}=V(Z)+z_{i} V^{\prime}(Z)+q$. A symmetric configuration has $Z=m z$, and hence the Nash-equilibrium condition is

$$
V(m z)+z V^{\prime}(m z)+q=c
$$

Equations $\left(1^{\prime}\right),\left(2^{\prime}\right)$ and $\left(4^{\prime}\right)$, together with the condition for the total number of consumers, $w$, describe the symmetric counterfeiting equilibrium. ${ }^{10}$ The status of each brand is determined by (2'), and, as noted, lies outside the

10. Counterfeiting occurs under oligopoly if $c-q>V\left(m x^{*}\right)+x^{*} V^{\prime}\left(m x^{*}\right)$, where $\mathrm{X}^{*}$ satisfies $\mathrm{S}\left(\mathrm{x}^{*}, \mathrm{mx^{* }}\right)=\mathrm{q}-\mathrm{a}$. 
control of the individual oligopolist. Outputs per firm are given by (4'), and these determine the market-clearing premium for high-quality goods according to (1'). Markups over marginal cost are limited here both by competition among the branded items and by the presence of counterfeits. The heterogenous consumers sort themselves according to taste, with those who value quality and status most highly purchasing genuine, brand-name items and those who place the least value on watches buying generics. Counterfeiters capture the consumers with intermediate tastes.

\section{WELFARE AND POLICY ANALYSIS}

\section{A. Enforcement and Confiscation Policy}

We now are ready to consider the welfare implications of counterfeiting, and to study alternative policies that might be used by the home government to combat this illegal practice. We begin by investigating the efficacy of enforcement activity. We capture this policy by exogenously varying the fraction $\phi$ of counterfeits that are detected and confiscated. Of course, there are costs involved in devoting resources to inspection at the border and to the search for counterfeits in the domestic marketplace. Here we focus only on the potential benefits of more vigilant enforcement, since little information is available on the functional relationship between government outlays and $\phi$.

We adopt as our welfare standard the unweighted sum of producers' surplus, consumers' surplus and government revenue. ${ }^{11}$ Aggregate (operating) profits are given by

11. We do not account for any welfare effects caused when third parties mistake a counterfeit product for a genuine one. 


$$
\mathrm{m} \pi=(\mathrm{p}-\mathrm{c}) \mathrm{mz},
$$

while aggregate consumer surplus is ${ }^{12}$

$$
\begin{aligned}
C S=\int_{0}^{m z}\{H(y)+S(x, y)-p\} d y+\int_{m z}^{m x}\{L(y) & +S(x, y)-q\} d y \\
& +\int_{m x}^{w}\{L(y)-a\} d y .
\end{aligned}
$$

Confiscation yields revenue for the government, if the illicit goods that are seized by the government are sold at auction. Current U.S. policy gives the enforcement agencies the option of whether to do so, or whether instead to destroy this merchandise. In our model, it is optimal for the government to sell whatever it confiscates. ${ }^{13}$ However, it seems reasonable to assume that the government would in fact destroy the counterfeits, if it were not possible for it to remove the illegally copied markings and other design features that manifest the violation of the trademark laws. Otherwise, the government would itself become a purveyor of counterfeits. Here we assume that it is in fact costly to obliterate the offending marks, so the government chooses to destroy any counterfeits that it captures. (See Picture 1.) of course, the welfare evaluation of enforcement policy would be somewhat more favorable if the government could easily transform confiscated items into generic products.

12. For ease of notation, we assume without further loss of generality that the consumer who is indifferent between purchasing a generic watch and none at all is the one with the highest index among those buying generics; i.e., with index $w$. In general, the last integral in (6) is taken over the set of consumers of generic products, whatever their indexes happen to be.

13. This is not necessarily the case when deceptive counterfeiting is involved, even if the government sells the goods that it confiscates as accurately-labeled generics. See Grossman and Shapiro (1986). 
With government revenue equal to zero, aggregate welfare, $W$, is the sum of the expressions in (5) and (6). Now, an increase in $\phi$ simply translates into an increase in $q$, the cost of delivering a counterfeit to the market. Differentiating $W$ with respect to $q$, we find

$$
\frac{d W}{d q}=\left\{\int_{0}^{m x} S_{x}(x, y) d y\right\} \frac{d x}{d q}+(p-c) \frac{d z}{d q}-m(x-z) .
$$

The first term on the right-hand side of (7) measures the change in status enjoyed by consumers of brand-name and counterfeit products. The second term captures the welfare effect of changes in high-quality output, in view of the market power of the oligopolists that causes $p$ to exceed $c$. The final term identifies an unambiguous social cost of stricter enforcement with subsequent destruction of the confiscated merchandise: confiscation raises the price of counterfeits, $q$, above their marginal cost of production, $b$. In effect, the perfectly competitive foreign producers must be compensated (on average) for their efforts, whether or not their output reaches the consumer. Destruction of some of this output implies a waste of foreign resources, the incidence of which falls entirely on domestic consumers of counterfeits. ${ }^{14}$

The $d x / d q$ and $d z / d q$ terms in (7) are computed from equations $\left(2^{\prime}\right)$ and $\left(4^{\prime}\right)$, respectively. It is easy to show that $\mathrm{dx} / \mathrm{dq}<0$ : by raising the cost of delivering a counterfeit to the market, tighter enforcement causes more consumers to choose generics goods. This augments social welfare due to the negative externality that these marginal consumers otherwise impose on the remaining

14. If $b>a$, some social cost of confiscation exists even when the seized goods are relabeled and sold as generics. Then resources are wasted in creating look-alikes that are not ultimately sold as such, and again domestic consumers of counterfeits must pay for this waste. 
status-conscious owners of branded watches. Also, $\mathrm{dz} / \mathrm{dq}>0$ (provided that the initial oligopoly equilibrium is stable ${ }^{15}$ ), as more consumers select high-quality watches over the now-more-expensive replicas. This effect too is welfare improving, since it offsets an existing oligopoly distortion. However, it is not possible to conclude that these two social benefits of stricter enforcement will, in general, outweigh the negative effect noted above.

There are, however, fairly general conditions under which social welfare rises with $q$ (and hence $\phi$ ) in a counterfeiting equilibrium. These (sufficient) conditions ensure that the status gain experienced by consumers of high-quality and counterfeit products exceed the social cost associated with the destruction of the copies. Suppose that consumers who value status highly also value it highly at the margin; i.e. $S_{x y} \geq 0$. Suppose further that there are a large number of consumers who value status nearly as much as does the marginal consumer of counterfeits; i.e., $\mathrm{s}_{\mathrm{y}}(\mathrm{x}, \mathrm{mx})$ is small. Then absent any costs of enforcement, an increase in the probability of confiscation must raise social welfare. (We prove this statement in the appendix.) In particular, these conditions are met if all consumers value status equally. Then, $S_{y}(x, y)=0$, and $d W / d q=$ $(\mathrm{p}-\mathrm{c}) \mathrm{m}(\mathrm{dz} / \mathrm{dq})+\mathrm{m}(\mathrm{x}-\mathrm{z})>0$.

\section{B. Regime Comparisons}

Our analysis of enforcement policy is useful for considering the welfare implications of the feasibility of counterfeiting. The overall effect of illegal copying on the efficiency properties of the market, for a status good can be found

15. From ( $\left.4^{\prime}\right)$, an increase in $q$ caused by an increase in $\phi$ is just like a decrease in $c$, so far as the effect on $Z$ is concerned. Seade (1985) and Dixit (1986) demonstrate that a symmetric decrease in oligopolists' costs raises industry output if the initial equilibrium is stable. In our model, the stability condition is $(m+1) V^{\prime}(Z)+Z V^{\prime \prime}(Z)<0$. 
by comparing the counterfeiting equilibrium described by (1'), (2') and (4') with the equilibrium that would prevail if counterfeiting were not possible. The latter equilibrium corresponds to a situation where $\phi=1$.

However, this regime comparison cannot be accomplished simply by integrating up to $q=+\infty(\phi=1)$ the expression for $d W / d q$ from (7). This is because (7) applies only within the range of $q$ that yield strictly positive sales of counterfeits. For q large enough ( $\phi$ close to one), no counterfeiting occurs. Yet, for a range of values of $q$, the threat of entry by counterfeiters still affects the equilibrium, outcome. In these limit-pricing equilibria, the trademark holders are prevented from raising the prestige of their products by reducing output, because doing so would make counterfeits attractive to some marginal consumers. In terms of Figure 1, limit-pricing equilibria arise when the oligopolist's marginal cost curve intersects its marginal revenue curve at the discontinuity in the latter.

Once the cost of delivering a counterfeit is high enough so that legitimate producers find it profitable to deter entry, further increases in $\phi$ have rather different effects than those described above for counterfeiting equilibria. In a limit-pricing equilibrium, an increase in counterfeiters' costs allows the trademark owners to cut their outputs to augment the prestige of their products, while still avoiding being copied. Such declines in sales exacerbate the oligopoly distortion, but ameliorate the consumption externality. Either of these two effects may dominate. Thus, aggregate welfare may increase or decrease as we raise $\phi$ in the range of limit-pricing equilibria.

In sum, we find that foreign counterfeiting of status goods has ambiguous welfare implications for the importing economy. Total industry output of authentic, brand-name products may be higher or lower in a counterfeiting equilibrium than in the equilibrium that would obtain instead if copying were 
infeasible. Counterfeits do impose negative status externalities on owners of prestige goods, but they also allow status appeal and quality to be unbundled, to the benefit of other consumers.

\section{Tariffs on Low-Quality Imports}

In many industries, government enforcement policy has not been an effective deterrent to counterfeiters. ${ }^{16}$ often, the illegal markings are not added to the counterfeits until after the goods have cleared customs in the importing country. And it is difficult indeed for the enforcement agents to monitor the whereabouts and condition of imported products once they have passed through the borders. In other cases, the imported copies are branded with markings that simulate but do not copy exactly the protected trademark of the legitimate producer, so that the customs officials may lack the legal authority to seize the offending items. In still other cases, look-alike products are smuggled into the country amidst shipments of legitimate, generic goods. For these and other reasons, the detection and confiscation rate for counterfeits of many items remains quite low.

As a result, industry lobbying groups such as the International Anticounterfeiting Coalition have sought alternative policies for combatting counterfeit-product trade. One proposal that has found favor among some policy makers is the erection of tariff barriers against imports from countries that are known to harbor counterfeiters. A similar sentiment underlies the recent amendment to the U.S. Trade and Tariff Act granting the President the authority to deny tariff preferences to countries that tolerate trademark violations.

16. See, for example, the testimonies of William Ellis (President, National Sales Audit), William Galloway (private investigator), Stanley J. Yavner (attorney on behalf of Calvin Klein and Members Only) and Craig 0. Correll (associate general counsel for Ocean Pacific Sunwear) before the Subcommittee on Oversight and Investigations, U.S. House of Representatives Committee on Energy and Commerce (1984). 
While such measures may be intended principally as threats to coerce foreign governments to police their local manufacturers, it is worthwhile to ask what implications tariffs would have for the efficiency of markets with traded counterfeits. We turn to this question now.

We introduce into our model a specific tariff at rate $t$ on all low-quality imports. Implicitly we are assuming that the counterfeits enter the country either without illegal markings or as part of a shipment of generic products, so that they would be subject to the same tariff treatment as other low-quality items. With the tariff in place, the domestic price of legitimate imports becomes $a+t$, while counterfeits sell for $q=(b+t) /(1-\phi)$. The latter expression incorporates the assumption that duty is paid on all counterfeits; the risk of confiscation occurs only after the goods clear customs.

Aggregate welfare now includes revenue from the tariff, $\operatorname{tm}(x-z) /(1-\phi)+$ $t(w-m x)$, which is the sum of the duties collected on counterfeits and on legitimate, low-quality products. Differentiating the resulting expression for $W$, we find

$$
\frac{d W}{d t}=\left\{\int_{0}^{m x} s_{x}(x, y) d y\right\} \frac{d x}{d t}+(p-c) m \frac{d z}{d t}+\frac{t m}{(1-\phi)}\left[\phi \frac{d x}{d t}+(1-\phi) \frac{d w}{d t}-\frac{d z}{d t}\right] .
$$

It is straightforward to show that $\mathrm{dx} / \mathrm{dt}<0, \mathrm{dz} / \mathrm{dt}>0$, and $\mathrm{dw} / \mathrm{dt}<0$. Intuitively, the tariff causes some consumers to substitute generic products for fakes, because, to the extent that duty is collected on some counterfeits that ultimately are confiscated, the prices of the copies rise by more than those of the legitimate imports. The tariff increases the demand for high-quality goods, which causes industry output to expand in a stable oligopoly equilibrium. Finally, the higher cost of generic products induces some marginal consumers to drop out of the market entirely. 
An increase in the tariff rate has three effects on social welfare. First, it raises the status level of existing branded products (both legitimate and counterfeit). Second, like confiscation policy, it offsets the existing oligopoly distortion. Finally, the tariff introduces the usual consumption distortion associated with a fall in the quantity of imports. Since this last effect is small for tariff rates near zero, we conclude that a small tariff on imports of low-quality goods always is welfare improving.

The primary benefit from a tariff in a market with counterfeit status goods is not what one might expect. Although the tariff does restore some of the lost prestige of brand-name goods, this effect is likely to be small in most applications. Indeed, the status-enhancement effect vanishes as the probability of confiscation approaches zero ${ }^{17}$. Rather, import protection is effective in this instance because it is pro-competitive. The supply of high-quality products increases as trademark owners respond to the upward shift in the supply curves of their fringe competitors.

Finally, we note that a large tariff can be harmful here for the usual reasons, and for some new ones. Any tariff causes $w$, the total number of consumers of watches, to be too small. A large enough tariff also may push $x$ to a suboptimally low level, or $z$ too high. Although counterfeiters always impose negative externalities in our model, they also provide prestige to a range of consumers who otherwise would not enjoy these benefits. Similarly, with protection in place, some consumers purchase quality in order to buy status, when these consumers would enjoy more surplus by selecting only the latter attribute of the product under free trade. For $t$ large, the social cost of distorting the

17. Note that $\left[S_{x}(x, m x)+m S_{y}(x, m x)\right] d x / d t=\phi /(1-\phi)$, so $\phi=0$ implies $d x / d t=0$. 
margins for choosing counterfeits can outweigh the benefits from reducing their number.

IV. Free Entry by Trademark Owners

So far we have taken the number of status goods, $m$, as given. This is appropriate in the short run, and in the long run if there are significant barriers to entry into the provision of status goods. If there are no such entry barriers, however, then the long-run effect of foreign counterfeiting includes its impact on domestic firms' incentives to develop new products, and hence on the number of brands marketed.

In this section we explore the welfare consequences of stricter enforcement efforts when the number of status goods adjusts endogeneously. In addition to the effects identified earlier, we account here for the entry or exit of branded products on account of improved protection of trademark owners' property rights, i.e., an increase in $\phi$. In the usual case (identified below), an increase in $\phi$ raises the profits of each status good manufacturer, thereby inducing entry of additional brands. The presence of another brand reduces the sales and increases the status of each product. Entry also erodes the market power enjoyed by each trademark owner. But these social benefits must be weighed against the additional fixed costs $F$ that are incurred when a new brand is developed and introduced into the market. As we shall see, the market may or may not be biased towards too few brands, and thus the entry induced by more vigilant enforcement may or may not constitute a welfare benefit.

In the free entry equilibrium, the number of firms, m, adjusts until

$$
(p-c) z=F
$$


i.e., until each firm earns zero economic profits. Equations (1'), (2'), (4'), and $\left(5^{\prime}\right)$ determine the variables $z, x, p$, and $\mathrm{m}$. Since profits are zero, welfare is simply given by consumer surplus, (6). Differentiating (6) with respect to $q$ gives

$$
\frac{d W}{d q}=\left\{\int_{0}^{m x} s_{x}(x, y) d y\right\} \frac{d x}{d q}-m z \frac{d p}{d q}-m(x-z) .
$$

Accounting for entry, there are three effects of increased enforcement efforts, each captured by a term on the right-hand side of (9). First, the size of each brand's network, $x$, changes. This affects the status enjoyed by consumers of high-quality products and counterfeits. This effect is similar to the first term in (7), but $d x / d q$ is altered by the possibility of entry. Second, the price paid for high-quality items changes. Any price decrease, for example, redounds to the benefit of consumers. ${ }^{18}$ Finally, as in Section III above, increased enforcement causes more counterfeits to be destroyed; consumers of counterfeits must pay for this waste in the form of the higher price $q$.

To explore $\mathrm{dW} / \mathrm{dq}$ more fully, we use equations $\left(1^{\prime}\right)-\left(5^{\prime}\right)$ to compute

$$
\begin{aligned}
& \frac{d p}{d q}=\frac{-E}{2 m-E}, \\
& \frac{d x}{d q}=\frac{1-x S_{y}(x, m x)\left(\frac{d m}{d q}\right)}{S_{x}(x, m x)+S_{y}(x, m x)}
\end{aligned}
$$

and

18. In the case of a fixed number of brands, price effects dropped out of the welfare expression, (7), because prices, p, were transfers from consumers to home firms. With free entry, however, profits are zero, and increased prices must be balanced against the benefits of the entry that they induce. These benefits come in the form of enhanced status. 


$$
\frac{\mathrm{dm}}{\mathrm{dq}}=\frac{\mathrm{m}(\mathrm{E}-2)}{z V^{\prime}(\mathrm{mz})[2 \mathrm{~m}-\mathrm{E}]} \text {, }
$$

where we have defined $E \equiv-Z V^{\prime \prime}(Z) / V^{\prime}(Z)$, the elasticity of the slope of the inverse demand curve for high-quality products. $2 m-E>0$ is the second-order condition for a firm's choice of $z$.

We focus here on the case in which an increase in counterfeiting costs, $q$, raises the profits of trademark owners, thereby inducing entry. In other words, we confine our attention to situations in which dm/dq $>0$. According to (12), $\mathrm{dm} / \mathrm{dq}$ is positive if and only if $\mathrm{E}<2 .^{19}$ In this case, greater protection for trademarks does indeed promote the provision of status goods.

Whenever increased enforcement promotes the entry of new brands, it must also raise the status of each product. From equation (11), dm/dq $>0$ implies that $d x / d q<0$, and the first term in our welfare expression, (9), is positive. There are two reason why prestige is enhanced via stricter enforcement. First, as $q$ rises, marginal consumers (with index $\mathrm{mx}$ ) substitute generic goods for counterfeits. In addition, the entry of new products allows each brand to generate more snob appeal as fewer consumers purchase authentic or counterfeit versions of that brand; consumers can spread themselves among more brands, enhancing the status of each.

Turning to the price effect, we see that prices fall in response to stricter enforcement exactly when the demand curve for high-quality products is convex: $\mathrm{dp} / \mathrm{dq}<0$ if and only if $\mathrm{V}^{\prime \prime}>0$. This weak condition is met, for example, by all constant elasticity demand curves. So long as $V^{\prime \prime}>0$, increased protection for

19. E $<2$ is the condition required to insure that a decrease in costs raises oligopoly profits, as Seade (1985) shows. In our model, an increase in $q$ has exactly the same effect on the profits of trademark owners as does a decrease in c. For a linear $\mathrm{V}(\mathrm{Z})$ function, $\mathrm{E}=0$ and $\mathrm{dm} / \mathrm{dq}>0$. 
trademark owners actually leads to a decrease in the price charged for their products.

We now have provided rather weak conditions, succinctly described as $0<E<2,{ }^{20}$ which guarantee that increased enforcement both lowers the price of high-quality products and enhances their prestige. Under these conditions, the first two terms in (9) are positive. But the third term in (9), the term capturing the wasted resources used in producing counterfeits that are to be destroyed, is of course negative. It is not possible in general to compare the two positive terms with this last term. Consequently, when we account for entry of new status products, we cannot be sure that welfare is enhanced by increased enforcement.

As in Section III, there are some simple conditions on tastes for status that are sufficient to insure a positive welfare effect of an increase in $\phi$. Specifically, the conditions $S_{x y} \geq 0$ and $S_{y}(x, m x)=0$ again guarantee $d W / d q>0$, irrespective of the form of $V(Z) .^{21}$ When all consumers value status equally, i.e., $s_{y} \equiv 0$, increased enforcement efforts do indeed generate social benefits, despite the waste that such efforts necessitate.

\section{Conclusions}

Counterfeit products are a significant and growing element in international trade. In some circumstances, the profitability of counterfeiting requires that unscrupulous producers be able to deceive consumers regarding the quality of

20. For example, if the function $V(\cdot)$ has constant elasticity, then $\mathrm{E}$ falls between zero and two if the demand elasticity exceeds unity.

21. The proof of this claim runs along the same lines as the proof in the appendix, after substituting for $d x / d q$ and $d p / d q$ from (10) and (11) into (9). 
their products. Yet many consumers who purchase counterfeits are well aware of the fact that they are buying forgeries. In these instances, consumers' willingness to pay premia for copies suggests that they value the prestige associated with the look-alike of a name brand. These premia compensate importers for bearing the risk of confiscation.

When consumers place a status value on name-brand merchandise, counterfeits serve to unbundle the quality and prestige attributes of branded products. As such, counterfeiting allows some consumers to enjoy the status of displaying a prestigious label without paying for a high-quality product. Yet these consumers impose a negative externality on other individuals who purchase genuine merchandise, the status of which is degraded by the presence of imitations. And the presence of forgeries alters the supply of legitimate, high-quality merchandise by oligopolistic trademark owners.

In view of these disparate effects of counterfeiting, policies designed to discourage foreign counterfeiting need not improve domestic welfare. One policy response to counterfeiting is to impose a tariff on low-quality imports. Tariffs do lower the volume of counterfeit-product trade. They also increase the supply of high-quality merchandise, thereby correcting the distortion caused by the fact that trademark owners have some market power. For these reasons, a small tariff is certainly welfare-improving. But larger tariffs may discourage some consumers from purchasing counterfeits, even when it is efficient for them to do so.

Much of our analysis is directed at enforcement policy, which we model through the probability of confiscation for a given counterfeit product. Generally, enhanced enforcement raises the status of brand-name goods (and of any remaining counterfeits), and induces trademark owners to expand their supply of high-quality products. But increased enforcement necessarily implies that more counterfeits are imported for every one that reaches a final consumer. Given 
perfectly elastic foreign supplies of counterfeits, the costs of any counterfeits that are produced and later destroyed must ultimately be borne by domestic consumers. For this reason, it is not true in general that stricter enforcement is welfare-improving, even when one ignores the direct costs associated with policing activities. We do find, however, that domestic welfare rises with the probability of confiscation when all consumers place an equal value on prestige. 


\section{APPENDIX}

Proposition: In a counterfeiting equilibrium, if $S_{x y} \geq 0$ and $S_{y}(x, m x)$ is small, then an increase in the probability of confiscation, $\phi$, raises social welfare.

Proof: We rewrite the equation for $\mathrm{dW} / \mathrm{dq}$ for convenience.

$$
\frac{d W}{d q}=\left\{\int_{0}^{m x} S_{x}(x, y) d y\right\} \frac{d x}{d q}+(p-c) \frac{d z}{d q}-m(x-z)
$$

The second term in (7) is unambiguously positive, since $\mathrm{dz} / \mathrm{dq}>0$. If $\mathrm{s}_{\mathrm{xy}} \geq 0$, then $\int_{0}^{m x} S_{x}(x, y) d y \leq m x S_{x}(x, m x)$ and the sum of the first and third terms exceeds

$$
m x S_{x}(x, m x) \frac{d x}{d q}-m x
$$

Now, by differentiating $\left(2^{\prime}\right)$, we find

$$
\frac{d x}{d q}=\frac{1}{S_{x}(x, m x)+m S_{y}(x, m x)}
$$

Substituting (A2) into the expression in (A1) yields

$$
m x \frac{S_{x}(x, m x)}{S_{x}(x, m x)+m S_{y}(x, m x)}-m x=m x\left[\frac{-m S_{y}(x, m x)}{\left.S_{x}(x, m x)+m S_{y}(x, m x)\right]} .\right.
$$

But $S_{y}(x, m x)$ small implies that the right-hand side of (A3) is small as well, so that $\mathrm{dW} / \mathrm{dq}>0$.

Q.E.D. 


\section{$\underline{\text { References }}$}

Business Week, "The Counterfeit Trade: Illegal Copies Threaten Most Industries -- And Can Endanger Consumers," December 16, 1985, pp.64-72.

Bhagwati, Jagdish N. and Hansen, Bent (1973), "A Theoretical Analysis of Smuggling," Quarterly Journal of Economics, 87, pp.172-187.

Dixit, Avinsah K. (1986), "Comparative Statics for 0ligopoly," International Economic Review, 27, forthcoming.

Ethier, Wilfred J. (1986), "Illegal Immigration: The Host Country Problem," American Economic Review, 76, pp.56-71.

Grossman, Gene M. and Shapiro, Car1 (1986), "Counterfeit-Product Trade," Woodrow Wilson School Discussion Papers in Economics No. 107, Princeton University.

Leibenstein, Harvey S. (1950), "Bandwagon, Snob and Veblen Effects in the Theory of Consumer's Demand," Quarterly Journal of Economics, 64, pp.183-207.

Martin, Lawrence and Panagariya, Arvind (1984), "Smuggling, Trade, and Price Disparity: A Crime-Theoretic Approach," Journal of International Economics, 17 , pp. 201-218.

New York Times, "Taiwan Curbs Its Counterfeiters," March 30, 1986.

Pitt, Mark M. (1981), "Smuggling and Price Disparity," Journal of International Economics, 11, pp.447-458.

Seade, Jesus (1985), "Profitable Cost Increases and the Shifting of Taxation: Equilibrium Responses of Markets in 0ligopoly", unpublished paper, University of Warwick.

United States House of Representatives Committee on the Judiciary (1985), "Trademark Counterfeiting Act of 1984," Hearings before the Subcommittee on Crime, Serial No. 151.

United States House of Representatives Committee on Energy and Commerce (1984), "Unfair Foreign Trade Practices: Part 3," Hearings Before the Subcommittee on Oversight and Investigations, Serial No. 98-164.

United States International Trade Commission, (1984) The Effects of Foreign Product Counterfeiting on U.S. Industry, USITC Publication 1479. 
Price $\mathrm{p}$

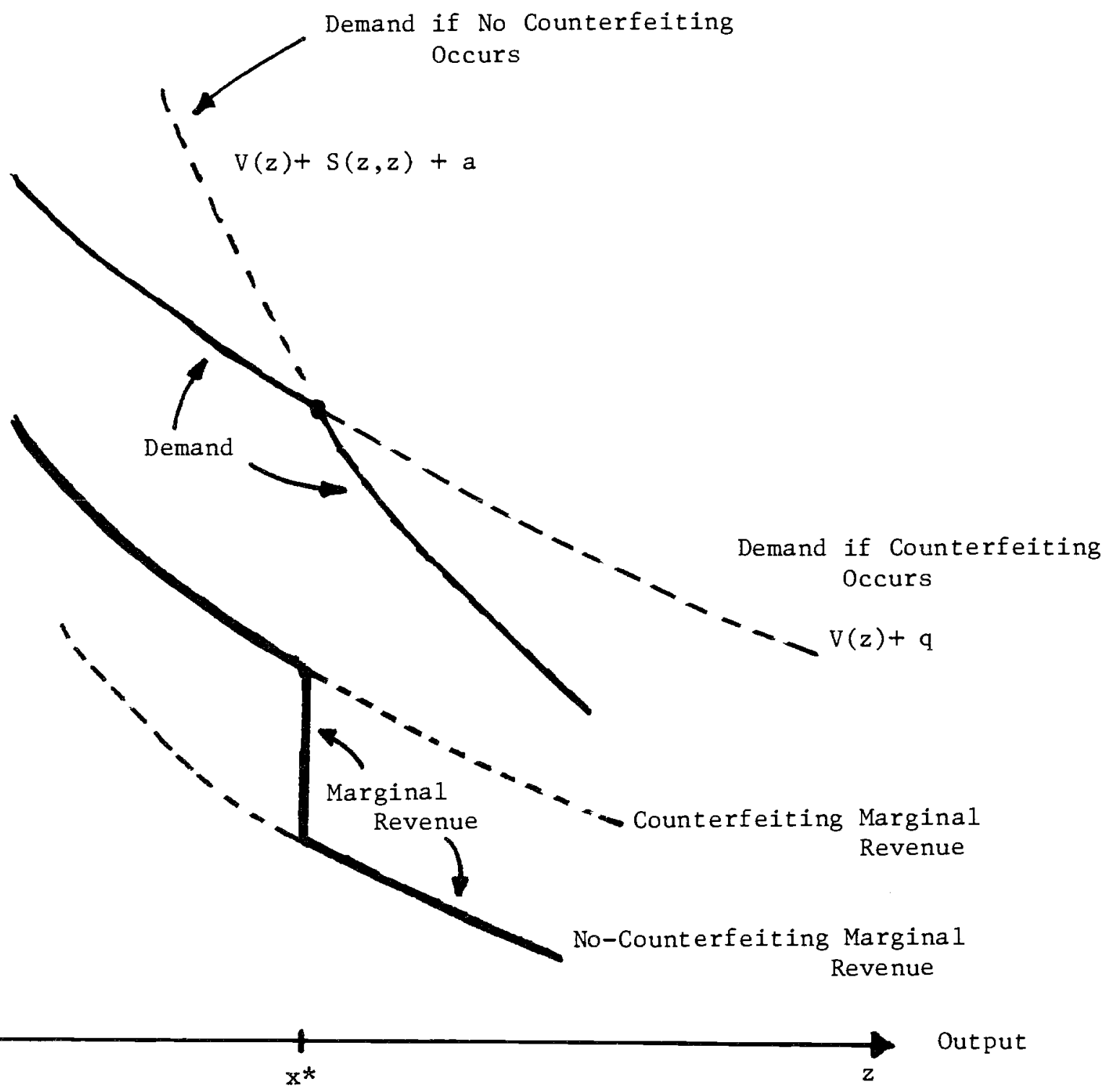

Figure 1

A Trademark Monopolist Facing a Fringe of Counterfeiters 


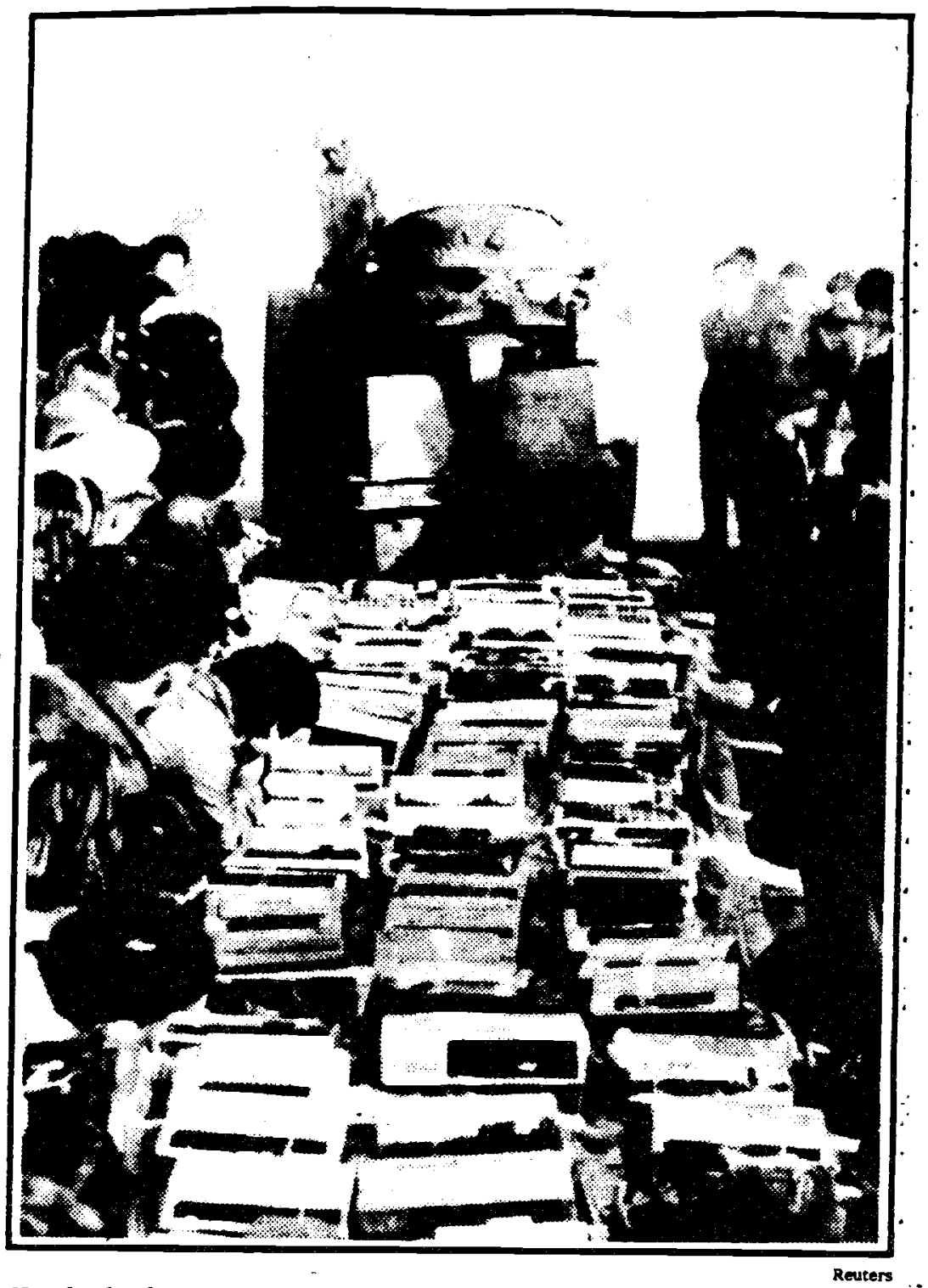

Hundreds of counterfeit computers being crushed by a road-roller

Picture 1

Destruction of Counterfeit Products 